\title{
KONSERVASI PENDIDIKAN KARAKTER ISLAMI DALAM HIDDEN CURRICULUM SEKOLAH
}

\author{
Fathurrohman \\ (Dosen DPK UIN Sunan Ampel di STAI Taruna Surabaya)
}

\begin{abstract}
Abstrak:
Pendidikan di negeri ini hingga sekarang masih menyisakan banyak persoalan, baik dari segi kurikulum, manajemen, maupun para pelaku dan pengguna pendidikan. SDM Indonesia masih belum mencerminkan cita-cita pendidikan yang diharapkan. Masih banyak ditemukan kasus seperti siswa melakukan kecurangan ketika sedang menghadapi ujian, bersikap malas dan senang bermain, hura-hura, senang tawuran antar sesama siswa, melakukan pergaulan bebas, hingga terlibat narkoba dan tindak kriminal lainnya. Kenyataan membuktikan bahwa Indonesia banyak bermasalah dalam hal karakter. Hal ini berarti bangsa Indonesia yang didominasi oleh umat Islam belum mengamalkan ajaran agama dengan baik. Untuk itu, perlu menjadikan pendidikan karakter Islami sebagai pondasi utama dalam membangun karakter manusia. Dengan agamalah karakter yang seutuhnya bisa dibangun. Namun demikian, untuk zaman sekarang masih diperlukan metode dan strategi yang dikembangkan oleh para ahli moral melalui hidden curriculum di sekolah.
\end{abstract}

Kata Kunci: Pendidikan Karakter dan Hidden Curriculum 


\section{A. Pendahuluan}

Kurikulum merupakan salah satu alat untuk mencapai tujuan pendidikan, dan sekaligus digunakan sebagai pedoman dalam pelaksanaan proses belajar mengajar pada berbagai jenis dan tingkat sekolah. Kurikulum menjadi dasar dan cermin falsafah pandangan hidup suatu bangsa; akan diarahkan kemana dan bagaimana bentuk kehidupan bangsa ini di masa depan, semua itu ditentukan dan digambarkan dalam suatu kurikulum pendidikan. Kurikulum haruslah dinamis dan terus berkembang untuk menyesuaikan berbagai perkembangan yang terjadi pada masyarakat dunia dan haruslah menetapkan hasilnya sesuai dengan yang diharapkan.

Pengertian kurikulum secara luas tidak hanya berupa mata pelajaran atau kegiatan-kegiatan belajar siswa saja tetapi segala hal yang berpengaruh terhadap pembentukan pribadi anak sesuai dengan tujuan pendidikan sehingga akhir-akhir ini muncul salah satu istilah hidden curriculum. Istilah hidden curriculum pertama kali digunakan oleh sosiolog Philip Jackson pada tahun 1968 M. Jackson berpendapat bahwa apa yang diajarkan di sekolah adalah lebih dari jumlah total kurikulum. Dia berpikir sekolah harus dipahami sebagai sebuah proses sosialisasi dimana siswa mengambil pesan melalui pengalaman di sekolah, bukan hanya dari hal-hal yang diajarkan secara eksplisit. Jika ingin mencari hidden curriculum, maka harus melihat apa yang tidak ada pada silabus. ${ }^{1}$

Pendidikan di negeri ini hingga sekarang masih menyisakan banyak persoalan, baik dari segi kurikulum, manajemen, maupun para pelaku dan pengguna pendidikan. SDM Indonesia masih belum mencerminkan cita-cita

\footnotetext{
${ }^{1}$ Michael Apple, "Hidden in Plain Sight, dalam Journal The Formal, Informal, and Hidden Curriculum of a Psychiatry Clerkship, Vol. 84 Nomor 2 (Mey, 2009), 451457.
} 
pendidikan yang diharapkan. Masih banyak ditemukan kasus seperti siswa melakukan kecurangan ketika sedang menghadapi ujian, bersikap malas dan senang bermain, hurahura, senang tawuran antar sesama siswa, melakukan pergaulan bebas, hingga terlibat narkoba dan tindak kriminal lainnya.

Di sisi lain, masih ditemukan pula guru yang melakukan kecurangan-kecurangan dalam sertifikasi dan dalam penyelenggaraan ujian nasional (UN). Atas dasar inilah, pendidikan perlu direkonstruksi ulang agar dapat menghasilkan lulusan yang lebih berkualitas dan siap menghadapi "dunia" masa depan yang penuh dengan problema dan tantangan serta dapat menghasilkan lulusan yang memiliki karakter mulia, yakni: memiliki kepandaian sekaligus kecerdasan, memiliki kreativitas tinggi sekaligus sopan dan santun dalam berkomunikasi, serta memiliki kejujuran dan kedisiplinan sekaligus memiliki tanggung jawab yang tinggi. Dengan kata lain, pendidikan harus mampu mengemban misi pembentukan karakter (character building) sehingga para peserta didik dan para lulusannya dapat berpartisipasi dalam mengisi pembangunan dengan baik dan berhasil tanpa meninggalkan nilai-nilai karakter mulia.

Inilah permasalahan karakter yang melanda sebagian besar bangsa ini. Masih banyak karakter (negatif) lain yang sekarang berkembang bahkan menjadi budaya di tengahtengah masyarakat yang semakin memperparah problem bangsa dan negara. Karena itulah, tahun lalu (2010) presiden kembali mengajak seluruh rakyat Indonesia untuk bersamasama membangun kembali budaya dan karakter luhur bangsa yang sudah memudar. Nilai-nilai karakter mulia yang dimiliki bangsa dan negara Indonesia sejak berabad-abad dan sekarang sudah terkikis harus dibangun kembali terutama melalui pendidikan. Disinilah peran pendidikan karakter dalam hidden 
curriculum sekolah dalam membangun karakter yang islami agar menjadi generasi yang berbudi luhur, berakhlaq mulia yang sesuai dengan tujuan pendidikan.

\section{B. Pendidikan Karakter}

Secara etimologis, kata karakter (Inggris: character) berasal dari bahasa Yunani (Greek), yaitu charassein yang berarti "to engrave" (Ryan and Bohlin, 1999:5). Kata "to engrave" bisa diterjemahkan mengukir, melukis, memahatkan, atau menggoreskan (Echols dan Shadily, 1995:214). Dalam Kamus Bahasa Indonesia kata "karakter" diartikan dengan tabiat, sifat-sifat kejiwaan, akhlak atau budi pekerti yang membedakan seseorang dengan yang lain, dan watak. Karakter juga bisa berarti huruf, angka, ruang, simbul khusus yang dapat dimunculkan pada layar dengan papan ketik (Pusat Bahasa Depdiknas, 2008:682). Orang berkarakter berarti orang yang berkepribadian, berperilaku, bersifat, bertabiat, atau berwatak. $^{2}$

Pendidikan karakter merupakan sesuatu yang baik. Dalam Islam, karakter identik dengan akhlaq, yaitu kecenderungan jiwa untuk bersikap atau bertindak secara otomatis. Akhlaq yang sesuai ajaran Islam disebut dengan akhlaqul karimah atau akhlaq mulia yang dapat diperoleh melalui dua jalan. Pertama, bawaan lahir, sebagai karunia dari Allah. Contohnya adalah akhlaq para Nabi. Kedua, hasil usaha melalui pendidikan dan penggemblengan jiwa. ${ }^{3}$

Dari pengertian di atas dapat dipahami bahwa karakter identik dengan akhlaq, sehingga karakter merupakan nilai-nilai

\footnotetext{
2 Marzuki, Prinsip Dasar Pendidikan Karakter Perspektif Islam, PKn dan Hukum FISE UNY.

3 Erma Pawitasari http://insistnet.com/enamprinsip-pendidikan-karakterislami/
} 
perilaku manusia yang universal yang meliputi seluruh aktivitas manusia, baik dalam rangka berhubungan dengan Tuhan, dengan diri sendiri, dengan sesama manusia, maupun dengan lingkungan, yang terwujud dalam pikiran, sikap, perasaan, perkataan, dan perbuatan berdasarkan normanorma agama, hukum, tata karma, budaya, dan adat istiadat. Dari konsep karakter ini muncul konsep pendidikan karakter (character education). Kehendak merupakan awal terjadinya karakter pada diri seseorang, jika kehendak itu diwujudkan dalam bentuk pembiasaan sikap dan perilaku.

\section{Hidden Curriculum}

Hidden curriculum merupakan "hasil (sampingan) dari pendidikan dalam latar sekolah atau luar sekolah, khususnya hasil yang dipelajari tetapi tidak secara tersurat dicantumkan sebagai tujuan".4 Beragam definisi lain telah dikembangkan berdasarkan pada perspektif yang luas untuk mempelajari peristiwa ini. Segala bentuk pendidikan, termasuk aktivitas rekreasional dan sosial, dapat mengajarkan bahan-bahan pelajaran yang sebetulnya tak sengaja karena bukan berhubungan dengan sekolah tetapi dengan pengalaman belajar.

Menurut Syafi'i Ma'arif, hidden curriculum mencakup pengembangan nilai-nilai di sekolah, perhatian, dan penekanan yang diberikan berbeda-beda pula terhadap bidang atau subjek

${ }^{4}$ Jane Martin, What Should We Do with a Hidden Curriculum When We Find One? dalam The Hidden Curriculum and Moral Education. Ed. Giroux, Henry, dan David Purpel. Berkeley, (California: McCutchan Publishing Corporation, 1983), 122-139. 
yang sama, tingkat semangat guru-guru dan kondisi fisik dan iklim sosial sekolah. ${ }^{5}$

Menurut Nasution, kurikulum sebenarnya mencakup pengalaman yang direncanakan tetapi juga yang tidak direncanakan yang disebut dengan "hidden curriculum", seperti: cara anak menjawab, mencontek, sikap terhadap asatidz (guru), disiplin dalam belajar, membina mental diri, dan masih banyak hal lainnya. Dalam hal selanjutnya kurikulum dapat dipandang sebagai ideal / real curriculum, potential / actual, dan juga disebut hidden curriculum. ${ }^{6}$

Diantara macam-macam kurikulum pendidikan adalah kurikulum formal, informal, dan non formal. Kurikulum formal mencakup kegiatan di kelas dan bersifat terencana. Kurikulum non formal terdiri atas aktifitas-aktifitas yang juga direncanakan akan tetapi tidak berkaitan langsung dengan pelajaran akademis dikelas, dan keberadaan kurikulum ini dipandang sebagai pelengkap (suplemen) kurikulum formal. Disamping kurikulum-kurikulum tersebut, terdapat juga hidden curriculum, sebagaimana yang telah disebutkan diatas. Kurikulum ini antara lain berupa aturan-aturan tak tertulis dikalangan siswa.

Dari beberapa pendapat tentang hidden curriculum di atas, dapat diambil suatu pengertian bahwa dalam pelaksanaan pendidikan di sekolah terdapat kurikulum yang tertulis dan kurikulum tak tertulis. Oleh karena itu, seharusnya dua kurikulum tersebut, mendapatkan perhatian bukan hanya kurikulum yang tertulis dan direncanakan saja, agar

5 Syafii Maarif, "Historiografi dan Pengajaran Sejarah. Makalah (Padang: FPIPS IKIP Padang, 1995), 1.

${ }^{6}$ Nasution, Pengembangan Kurikulum, Cet. IV (Bandung: PT. Citra Aditya Bakti, 1993), 11. 
keberhasilan proses belajar mengajar dan hasil pendidikan sesuai dengan tujuan pendidikan nasional.

\section{Pendidikan Karakter dalam Hidden Curriculum Sekolah}

Mengutip artikel Dyah Kumalasari, Benson Snyder, para pendidik, sosiolog, dan psikolog dalam melukiskan sistem informal dalam dunia pendidikan. Hidden curriculum disebutkan terdiri atas tiga $\mathrm{R}$ yang sangat penting untuk dikembangkan yaitu rules (aturan), regulations (peraturan), dan routines (kontinyu). Dimana setiap sekolah yang menerapkan sistem ini harus beradaptasi. Sosialisasi nilai-nilai moral merupakan suplemen dari tiga $\mathrm{R}$, pelajaran atau mata kuliah tersebut juga akan semakin jelas dan mudah dipahami bila disampaikan dengan jalan klasikal dalam ruang kelas yang teratur. $^{7}$

Rumusan teori Benson Snyder yang dikenal dengan $3 \mathrm{R}$ ersebut sejalan dengan visi dan misi pendidikan, yaitu "beriman dan bertaqwa, berprestasi dan kompetitif, berbudi luhur". Salah satu diantaranya dengan kegiatan pengembangan diri siswa yang bersifat spontan dan keteladanan baik tersurat maupun tersirat yang dirancang dan dikembangkan seperti pembiasaan suasana religius di kawasan lingkungan sekolah.

Berbagai penelitian telah dilakukan pada kajian teori hidden curriculum. Dreeben mengakui hidden curriculum sebagai proses sosialisasi sekolah baik itu meliputi ideologi, keyakinan, nilai dan norma. ${ }^{8}$ Emile Durkheim mengamati bahwa hidden curriculum lebih banyak diajarkan dan dipelajari daripada kurikulum resmi, meskipun tidak secara langsung

7 Jeane H. Balantine, The Sociology of Education A Systematic Analysis (New Jersey: Intence Hall Inc, 1983).

8 Ibid., 83-88. 
disebutkan sebagai "hidden curriculum". ${ }^{9}$ Program konservasi pendidikan karakter ini harus dilaksanakan oleh semua warga sekolah dengan nilai-nilai agama yang kental bisa dilihat dalam kebiasaan anak-anak bersalaman kepada guru mereka, berperilaku sopan-santun kepada siapa saja bila bertemu, mengambil sampah setiap melihat sampah yang berserakan dan memasukkannya ke dalam bak sampah, dan lain-lain. Bentuk pengendaliannya lewat pantauan baik dilakukan oleh guru, wali kelas, maupun kepala sekolah.

Kajian ini juga mengungkapkan bagaimana cara mengatur program dalam mekanisme kegiatan pendidikan karakter. Hal ini sebaiknya dicantumkan dalam jadwal tersendiri yang diatur oleh kurikulum seperti di bawah ini:

1. Kegiatan pendidikan karakter yang bersifat rutin/ terstruktur dilaksanakan pada waktu pembelajaran efektif dengan mengalokasikan waktu khusus dalam jadwal pelajaran, dibina oleh guru dan konselor sekolah.

2. Kegiatan pendidikan karakter pilihan dilaksanakan di luar jam pembelajaran (ekstrakurikuler) dibina oleh guru, praktisi, atau alumni yang memiliki kualifikasi yang baik berdasarkan surat keputusan kepala sekolah. ${ }^{10}$

Dari pemaparan data di atas, ditemukan bahwa pendidikan karakter Islami ialah pembiasaan suasana religius di kawasan sekolah. yaitu; (1). Budaya S3AS (Salam, Salim, Senyum, Ambil Sampah), (2). Budaya Jum'at Bersih, (3). Halal Bihalal, (4). Peringatan Hari Besar Islam (PHBI), (5). Santunan Kematian, (6). Santunan Anak Yatim, (7). Budaya Anjang Sana

\footnotetext{
${ }^{9}$ Fulya Damla Kentli, “Comparison of Hidden Theories”, 83-88.

10 Dokumen perangkat pembelajaran PAI SDN Sawotratap I Gedangan-Sidoarjo tahun pelajaran $2013 / 2014$ 
keluarga Dewan Guru dan Karyawan, (8) Budaya Tasyakuran, dan (9). Budaya beramal jariyah setiap jum'at.11

Adapaun secara terperinci, kegiatan harian, mingguan, tahunan dan insidental dapat diuraikan sebagai berikut:

\section{Kegiatan Harian.}

a. Doa bersama. Kegiatan doa bersama-sama dilakukan setiap hari pada pagi hari tepatnya sebelum pelajaran dimulai, yang dipandu langsung dari radio sekolah dan dipimpin oleh guru yang bertugas secara bergantian.

b. Shalat dhuha. Shalat sunnah dhuha dilakukan oleh para guru dan siswa. Namum pelaksanaannya bukan merupakan kewajiban yang harus dilakukan oleh seluruh anggota masyarakat sekolah karena sifatnya mubah menurut peraturan sekolah. Di sisi lain ada guru yang setiap mau mengajar di pagi hari, guru tersebut sebelum memulai kegiatan belajar mengajar selalu mengajak peserta didik melaksanakan shalat sunnah Dhuha, setelah itu mengajak peserta didik untuk memasuki kelas

c. Pakaian wajib menggunakan busana muslim. Setiap peserta didik putri wajib memakai busana muslim yang intinya menutup aurat sebagai salah satu langkah pembiasaan berpakaian yang baik dan sopan. Sedangkan untuk yang non-muslim tidak ada kewajiban tapi harus menyesuaikan dengan aturan sekolah yakni berpakaian yang baik dan sopan.

d. Silaturrahim antara siswa dengan guru. Kegiatan silaturrahim dilakukan pada pagi hari yaitu sewaktu masyarakat sekolah memasuki lingkungan sekolah. Kegiatan ini dilakukan dengan cara kepala sekolah dan

11 Observasi yang dilakukan oleh penulis di SDN Sawotratap I GedanganSidoarjo pada Bulan Januari-Maret 2014. 
dewan guru berada di lobi sekolah menunggu datangnya peserta didik dan setiap peserta didik yang datang langsung bersalaman dengan para guru sampai bel masuk kelas berbunyi.

e. Pembiasaan salam, sapa, senyum, sopan, dan santun (5S). Pembiasaan ini dilakukan sebagai upaya untuk membiasakan masyarakat sekolah terbiasa dengan mendoakan orang lain dengan mengucapkan salam, ramah dengan menyapa orang di sekitarnya dan senyum sebagai lambang kedermawanan (bersadaqoh), sehingga terciptalah kesopanan dan kesantunan.

\section{Kegiatan Mingguan}

a. Kegiatan ibadah jumat setiap hari jum'at, keputrian pada jum'at siang dan shalat jum'at bagi peserta didik putra. Kegiatan ini sifatnya tidak mengikat.

b. Pengisian kotak amal setiap hari jum'at (infaq dan shadaqoh). Kegiatan ini di laksanakan pada semua kelas yang dikoordinir oleh masing-masing ketua kelas, yang kemudian hasilnya dijadikan satu untuk diberikan kepada fakir miskin dengan melibatkan siswa agar siswa terbiasa dengan sifat dermawan dan menjadi orang yang gemar berinfaq dan shadaqoh.

\section{Kegiatan Tahunan}

a. Peringatan hari besar Islam (PHBI) yang meliputi: peringatan Isro' Mi'raj, Nuzulul Qur'an, dan Maulid Nabi Muhammad SAW. Kegiatan ini dilakukan oleh seluruh warga sekolah pada tiap-tiap Peringatan Hari Besar Islam (PHBI). Ini dilakukan sebagai bentuk hubbud diniyah karena merupakan simbol-simbol agama Islam. 
b. Pelaksanaan sholat tarawih, tadarus, dan pembagian zakat fitra. Pelaksanaan shalat tarawih dilaksanakan secara bergantian mulai dari kelas IV, V, dan VI. Setelah pelaksanaan shalat tarawih diteruskan dengan mengadakan tadarus al-Qur'an. Sedangkan pada minggu terakhir dilakukan pengumpulan dan pembagian zakat fitrah.

c. Shalat Iedul Adha, pembagian daging Qurban. Di SDN Sawotratap I Gedangan-Sidoarjo juga melaksanakan shalat Iedul Adha di sekolah bekerjasama dengan walimurid sebagai bentuk peran serta masyarakat (PSM) dan diteruskan dengan penyembelihan hewan Qurban dan membagi-bagikannya kepada masyarakat.

d. Bakti sosial. Bakti sosial dilakukan ke warga desa yang berada disekitar lembaga SDN Sawotratap I GedanganSidoarjo.

\section{Kegiatan Insidental}

a. Takziyah. Kegiatan takziyah dilaksanakan dengan menyertakan siswa di kelas itu, wali kelas, guru yang mengajar dan juga Paguyupan Kelas selaku pengumpul dana untuk pelaksanaan ta'ziyah.

b. Menjenguk orang sakit. Kegiatan ini dilaksanakan ketika ada peserta didik yang sakit.

Dengan demikian, karakter telah melekat dalam diri peserta didik secara fitriah. Dengan kemampuan fitriah ini, peserta didik mampu membedakan batas kebaikan dan keburukan, dan mampu membedakan mana yang tidak bermanfaat dan mana yang bermanfaat. Harus dipahami bahwa pembawaan fitrah peserta didik ini tidak serta merta menjadikan karakter peserta didik bisa terjaga dan berkembang sesuai dengan fitrah tersebut. Fakta membuktikan 
bahwa pengalaman yang dihadapi masing-masing orang menjadi faktor yang sangat dominan dalam pembentukan dan pengamalan karakternya. Di sinilah pendidikan karakter dalam hidden curriculum mempunyai peran yang penting dan strategis bagi peserta didik dalam rangka melakukan proses internalisasi dan pengamalan nilai-nilai karakter mulia di masyarakat.

\section{E. Kesimpulan}

Kenyataan membuktikan bahwa Indonesia banyak bermasalah dalam hal karakter. Hal ini berarti bangsa Indonesia yang didominasi oleh umat Islam belum mengamalkan ajaran agama dengan baik. Untuk itu, perlu menjadikan pendidikan karakter Islami sebagai pondasi utama dalam membangun karakter manusia. Dengan agamalah karakter yang seutuhnya bisa dibangun. Namun demikian, untuk zaman sekarang masih diperlukan metode dan strategi yang dikembangkan oleh para ahli moral melalui hidden curriculum di sekolah.

\section{DAFTAR PUSTAKA}

Dokumen perangkat pembelajaran PAI SDN Sawotratap I Gedangan-Sidoarjo tahun pelajaran 2013/2014

Erma Pawitasari http://insistnet.com/enamprinsip-pendidikankarakter-islami/

Jane Martin, What Should We Do with a Hidden Curriculum When We Find One? dalam The Hidden Curriculum and Moral Education. Ed. Giroux, Henry, dan David Purpel. Berkeley, (California: McCutchan Publishing Corporation, 1983). 
Jeane H. Balantine, The Sociology of Education A Systematic Analysis (New Jersey: Intence Hall Inc, 1983).

Marzuki, Prinsip Dasar Pendidikan Karakter Perspektif Islam, PKn dan Hukum FISE UNY.

Michael Apple, "Hidden in Plain Sight, dalam Journal The Formal, Informal, and Hidden Curriculum of a Psychiatry Clerkship, Vol. 84 Nomor 2 (Mey, 2009).

Nasution, Pengembangan Kurikulum, Cet. IV (Bandung: PT. Citra Aditya Bakti, 1993).

Fulya Damla Kentli, "Comparison of Hidden Theories".

Observasi yang dilakukan oleh penulis di SDN Sawotratap I Gedangan-Sidoarjo pada Bulan Januari-Maret 2014.

Syafii Maarif, "Historiografi dan Pengajaran Sejarah. Makalah (Padang: FPIPS IKIP Padang, 1995). 